\title{
Acetate-buffered crystalloid infusate versus infusion of $0.9 \%$ saline and hemodynamic stability in patients undergoing renal transplantation
}

\author{
Prospective, randomized, controlled trial
}

\author{
Carmen Pfortmueller · Georg-Christian Funk · Eva Potura · Christian Reiterer · Florian Luf · Barbara Kabon · \\ Wilfred Druml · Edith Fleischmann · Gregor Lindner
}

Received: 8 January 2017 / Accepted: 6 February 2017 / Published online: 2 March 2017 (C) The Author(s) 2017. This article is available at SpringerLink with Open Access.

\begin{abstract}
Summary
Background Infusion therapy is one of the most frequently prescribed medications in hospitalized patients. Currently used crystalloid solutes have a variable composition and may therefore influence acidbase status, intracellular and extracellular water content and plasma electrolyte compositions and have a major impact on organ function and outcome. The aim of our study was to investigate whether use of acetate-based balanced crystalloids leads to better hemodynamic stability compared to $0.9 \%$ saline. Methods We performed a sub-analysis of a prospective, randomized, controlled trial comparing effects of $0.9 \%$ saline or an acetate-buffered, balanced crystal-
\end{abstract}

\footnotetext{
Institutional Review Board (IRB) contact information The study was approved by the local institutional review board (EK 1048/2009 and EK 1828/2014), of the Medical University of Vienna, Austria, and registered at a clinical trials registry (NCT01075750). Written informed consent was obtained from every patient included in the study; this report describes a prospective randomized clinical trial. The authors state that every item in the CONSORT checklist is included in the report; Registry Url: clincaltrials.gov Identifier: NCT01075750; this manuscript was screened for plagiarism using Plagiarism Checker.

C. Pfortmueller, MD ( $₫) \cdot$ E. Potura · C. Reiterer · F. Luf . B. Kabon · E. Fleischmann

Department of Anesthesiology, General Intensive Care Medicine and Pain Management, Medical University of Vienna, Spitalgasse 23, 1090 Vienna, Austria

cpfortmueller@gmail.com

\section{E. Potura}

eva.potura@meduniwien.ac.at

C. Reiterer

christian.reiterer@meduniwien.ac.at
}

loid during the perioperative period in patients with end-stage renal disease undergoing cadaveric renal transplantation. Need for catecholamine therapy and blood pressure were the primary measures.

Results A total of 150 patients were included in the study of which 76 were randomized to $0.9 \%$ saline while 74 received an acetate-buffered balanced crystalloid. Noradrenaline for cardiocirculatory support during surgery was significantly more often administered in the normal saline group, given earlier and with a higher cumulative dose compared to patients receiving an acetate-buffered balanced crystalloid (30\% versus $15 \%, p=0.027 ; 68 \pm 45 \mu \mathrm{g} / \mathrm{kg}$ versus $75 \pm 60 \mu \mathrm{g} / \mathrm{kg}, p=0.0055$ and $0.000492 \mu \mathrm{g} / \mathrm{kg}$ body

F. Luf

florian.luf@meduniwien.ac.at

B. Kabon

barbara.kabon@meduniwien.ac.at

E. Fleischmann

edith.fleischmann@meduniwien.ac.at

G.-C. Funk

Department of Respiratory and Critical Care Medicine, Otto Wagner Hospital Vienna and Ludwig-Boltzmann Institute for COPD and Respiratory Epidemiology, Vienna, Austria georg-christian.funk@meduniwien.ac.at

W. Druml

Department of Nephrology, Medical University of Vienna,

Vienna, Austria

wilfred.druml@meduniwien.ac.at

G. Lindner

Department of Emergency Medicine, Hirslanden - Klinik Im Park, Zurich, Switzerland

lindner.gregor@gmail.com 
weight $/ \mathrm{min}, \pm 0.002311$ versus $0.000107 \mu \mathrm{g} / \mathrm{kg} / \mathrm{min}$, $\pm 0.00039, p=0.04$, respectively). Mean minimum arterial blood pressure was significantly lower in patients randomized to $0.9 \%$ saline than in patients receiving the balanced infusion solution (57.2 [SD 8.7] versus 60.3 [SD 10.2] $\mathrm{mm} \mathrm{Hg}, p=0.024$ ).

Conclusion The use of an acetate-buffered, balanced infusion solution results in reduced need for use of catecholamines and cumulative catecholamine dose for hemodynamic support and in less occurrence of arterial hypotension in the perioperative period. Further research in the field is strongly encouraged.

Keywords Balanced · Crystalloid · Hemodynamic $\cdot$ Renal transplantation · Saline

\section{Introduction}

Infusion therapy is one of the most frequently prescribed medications in hospitalized patients. The importance of research on fluid therapy has been unrecognized for a long time with normal saline being the most popular infusate [1-4]. During recent years newer balanced infusates containing lactate or acetate became increasingly popular in many European countries whereas in the United States $0.9 \%$ saline is still the most widely used infusate in the perioperative and intensive care setting [4]. Currently used crystalloid solutions have a variable composition and may therefore influence acid-base status, intracellular and extracellular water content and plasma electrolyte compositions [5] and have a major impact on organ function and outcome [6]. Despite continuing evaluation no superiority of one particular type of fluid has been achieved so far [7-10]. Nonetheless during recent years it has been shown that the theoretically more physiologically balanced buffered infusion solutions may have a respectable advantage in terms of patient morbidity. A study on healthy human volunteers found a balanced chloride-reduced infusion solution to be associated with better mean renal artery flow velocity, renal cortical tissue perfusion and urine output than infusion of 21 of $0.9 \%$ saline [11]. In a further study including elderly surgery patients, gastric mucosal perfusion was reduced in patients receiving $0.9 \%$ saline compared to those receiving chloride-reduced infusion solutions [12]. These data, together with data from rodents with experimental sepsis, which showed significantly lower mean arterial pressure levels when receiving chloride-rich infusion solutions compared to lactated Ringer's, could suggest an effect of the crystalloid fluid used on a patients' hemodynamic situation [13].

In the present study we performed a sub-analysis using data from our previously performed prospective randomized controlled trial comparing an acetate-buffered balanced infusion solution compared to $0.9 \%$ saline in patients with end-stage renal disease receiving cadaveric renal transplantation [14]. Our aim was to investigate whether use of an acetatebuffered, chloride-reduced balanced infusion solution would result in A.) less need for catecholamine use than use of $0.9 \%$ saline and B.) in better hemodynamic stability of patients expressed by the mean arterial blood pressure.

\section{Material and methods}

\section{Setting}

The study was conducted at the Clinic of General Anesthesiology, Intensive Care and Pain Medicine of the Medical University of Vienna.

\section{Patients, randomization and study fluids}

All patients with end-stage renal disease undergoing cadaveric renal transplantation were included in the study. Patients younger than 18 years were excluded from the study as well as patients with a preoperative potassium concentration of more than $5.5 \mathrm{mmol} / \mathrm{l}$. Enrollment started on 1 June 2010 and terminated on 28 February 2013. Prior to enrollment the study was registered at clinicaltrial.org (NCT01075750).

Computer-based randomization was performed at time of transfer to the preoperative care unit of the Department of Anesthesiology. Patients either received normal saline (osmolality $308 \mathrm{mOsm} / \mathrm{kg}$ body weight, base excess $-24 \mathrm{mmol} / \mathrm{l}, \mathrm{Na}^{+} 154 \mathrm{mmol} / \mathrm{L}, \mathrm{Cl}^{-}$ $154 \mathrm{mmol} / \mathrm{L}$ ) or a chloride-reduced, acetate-buffered balanced crystalloid (Elomel Isoton ${ }^{\circledR}$, Fresenius Kabi Austria GmbH, Graz; osmolality $302 \mathrm{mOsm} / \mathrm{kg}$, base excess $0 \mathrm{mmol} / \mathrm{L}, \mathrm{Na}^{+} 140 \mathrm{mmol} / \mathrm{L}, \mathrm{K}^{+} 5 \mathrm{mmol} / \mathrm{L}, \mathrm{Cl}^{-}$ $108 \mathrm{mmol} / \mathrm{L}, \mathrm{Mg}^{++} 1.5 \mathrm{mmol} / \mathrm{L}, \mathrm{Ca}^{++} 2.5 \mathrm{mmol} / \mathrm{L}$, acetate $45 \mathrm{mmol} / \mathrm{L}$ ). No intravenous fluid was given prior to randomization. The following data were obtained from patients: age, sex, height, actual weight, dry weight, residual daily urine output, number of prior renal transplantations, total of fluid administered intraoperatively, total of fluid at start catecholamines, use of catecholamines, dose of catecholamines per $\mathrm{kg}$ body weight per min, time on catecholamines and cumulative vasopressor dose per $\mathrm{kg}$ body weight per min.

\section{Anesthesia}

Details on the anesthesia protocol are described elsewhere [14]. After intubation patients were fitted with a central venous line as well as a peripheral venous line.

\section{Hemodynamic management}

Intraoperatively a set infusion rate at $4 \mathrm{ml}$ per $\mathrm{kg}$ of ideal body weight per hour $(4 \mathrm{ml} / \mathrm{kg} / \mathrm{h})$ was infused. Hypotension was defined as a mean arterial pressure of less than $60 \mathrm{~mm} \mathrm{Hg}$. If hypotension occurred a fluid 
challenge with $250 \mathrm{ml}$ of infusate was conducted. Additional fluid boluses of $250 \mathrm{ml}$ were administered depending on volume reactivity (increase in mean arterial pressure or/and central venous pressure). If no reaction to volume challenge was seen a vasopressor (either phenylephrine or etilefrine) was administered. A maximum dose of $0.1 \mathrm{mg}$ of phenylephrine and $2 \mathrm{mg}$ of etilefrine was given at one time. If more than ten applications of vasopressor were necessary per hour or likely to exceed ten applications per hour (severe refractory hypotension) noradrenaline infusion was commenced. Additionally, repeated fluid boluses were administered if considered necessary by the anesthesiologist.

\section{Ethics}

The study was approved by the local institutional review board (EK 1048/2009 Oct 2009 and EK 1828/2014 Oct 2014, Chairman Prof. E. Singer), of the Medical University of Vienna, Austria, and registered at a clinical trials registry (NCT01075750). Written informed consent was obtained from every patient included in the study.

\section{Statistics}

The sample size calculation for the original study is described in detail elsewhere [14]. Statistical analysis was performed by SPSS version 17.0 (Chicago, IL). Distribution of interval variables was assessed using normal plots. Interval variables with a normal distribution are presented as means \pm standard deviation (SD). Non-normally distributed interval variables and ordinal variables are presented as medians with interquartile ranges (IR). Comparisons of normally distributed interval variables between the saline group and the acetate-buffered balanced crystalloid group were performed using Student's t-test. Comparisons of non-normally distributed interval variables and ordinal variables between the saline group and the acetate-buffered balanced crystalloid group were per- formed using Mann-Whitney U-test. Comparisons of categorical variables between the saline group and the acetate-buffered balanced crystalloid group were performed by the $\chi^{2}$-test.

In order to test whether mean arterial blood pressure differed between the saline group and the acetate-buffered balanced crystalloid group, we used a generalized estimating equation assuming a normal probability distribution and a first order exponential correlation matrix for repeated observations in one patient. In order to test for differences in the incidence of vasopressor administration between the two study groups, we used a log-rank test and a KaplanMeier plot for visualization. In order to test whether vasopressor use was anteceded by hypotension, we used a Cox regression with vasopressor use as the dependent variable and mean arterial blood pressure as the time varying predictor variable. For all analyses statistical significance was defined by a two-sided $P<$ 0.05 .

Figures were drawn using GraphPadPrism 5.01.

\section{Results}

A total of 150 patients were included in the study, 76 patients were randomized to normal saline and 74 patients to an acetate-buffered balanced crystalloid. No differences between the groups were found for the following parameters: age, sex, height, actual and dry weight, residual daily urine output, number of prior renal transplantations. For an overview on baseline characteristics see Table 1 . The CONSORT flow chart is given in Fig. 1.

In the $0.9 \%$ saline group the mean volume of fluid received during surgery was $1691 \pm 664 \mathrm{ml}$ compared to $1798 \pm 679 \mathrm{ml}$ in the balanced acetate-based infusate group $(p=0.34)$. Noradrenaline for cardiocirculatory support during surgery was administered significantly more often in the normal saline group compared to patients receiving an acetate-buffered balanced crystalloid (30\% versus $15 \%, p=0.027$ ). Patients receiving normal saline needed noradrenaline

Table 1 Baseline characteristics of patients. Results are mean \pm standard deviation or median (1st-3rd quartile)

\begin{tabular}{|c|c|c|c|c|c|c|c|}
\hline \multirow[b]{3}{*}{ Sex (male/female) } & \multicolumn{3}{|c|}{ Normal saline group } & \multicolumn{3}{|c|}{ Acetate-buffered balanced crystalloid group } & \multirow{3}{*}{$\begin{array}{l}p \text {-value } \\
0.99\end{array}$} \\
\hline & \multirow{2}{*}{$\begin{array}{l}\text { Count } \\
48 / 28\end{array}$} & \multicolumn{2}{|c|}{ Percent } & \multirow{2}{*}{$\begin{array}{l}\text { Count } \\
47 / 27\end{array}$} & \multicolumn{2}{|c|}{ Percent } & \\
\hline & & $63 / 37$ & - & & $64 / 36$ & - & \\
\hline Age (years) & 76 & 100 & $56 \pm 13$ & 74 & 100 & $54 \pm 13$ & 0.35 \\
\hline Height (cm) & 76 & 100 & $173 \pm 8$ & 74 & 100 & $172 \pm 10$ & 0.63 \\
\hline Dry weight (kg) & 76 & 100 & $80 \pm 18$ & 74 & 100 & $79 \pm 16$ & 0.79 \\
\hline Actual weight (kg) & 76 & 100 & $81 \pm 19$ & 74 & 100 & $80 \pm 16$ & 0.74 \\
\hline $\begin{array}{l}\text { Residual urine output } \\
\text { (ml/24 h) }\end{array}$ & 76 & 100 & $500(0-1000)$ & 74 & 100 & $\begin{array}{l}250 \\
(0-1000)\end{array}$ & 0.45 \\
\hline Prior kidney transplantation & 12 & 16 & - & 13 & 118 & - & 0.36 \\
\hline $\begin{array}{l}\text { Non-heart beating kidney } \\
\text { donor }\end{array}$ & 1 & 1.3 & - & 2 & 1.4 & - & 0.51 \\
\hline $\begin{array}{l}\text { Postoperative necessity for } \\
\text { hemodialysis }\end{array}$ & 19 & 25 & - & 19 & 25.7 & - & 0.49 \\
\hline
\end{tabular}




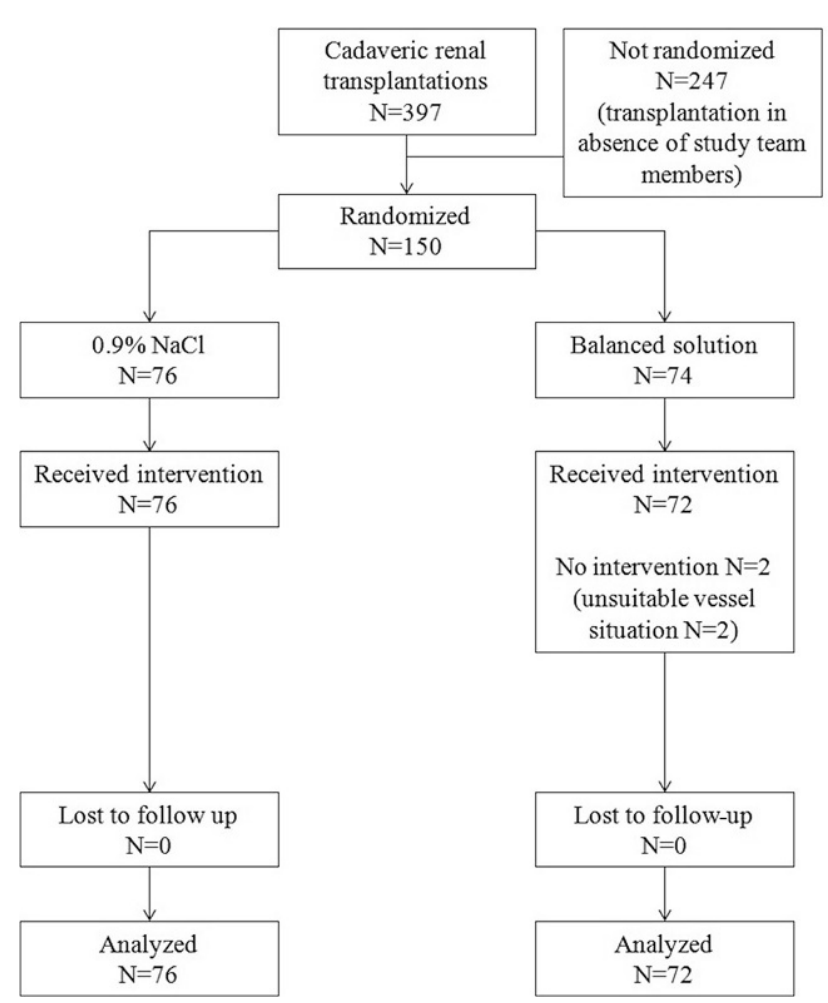

Fig. 1 Consolidated Standards of Reporting Trials (CONSORT) flow chart

significantly earlier and the cumulative noradrenaline dose was significantly higher than patients receiving an acetate-based crystalloid solute $(68 \mathrm{~min} \pm 45$ versus $75 \mathrm{~min} \pm 60, p=0.0055$ and $0.000492 \mu \mathrm{g} / \mathrm{kg}$ body weight $/ \mathrm{min}, \pm 0.002311$ versus $0.000107 \mu \mathrm{g} / \mathrm{kg} / \mathrm{min}$, $\pm 0.00039, p=0.04$, respectively). No difference in necessity for vasopressor or cumulative dose of vasopressors was seen between the groups ( $p=0.47$ and $p=0.08$, respectively) (see Table 2; Fig. 2).

Mean minimum arterial blood pressure was significantly lower in patients randomized to $0.9 \%$ saline than in patients receiving the balanced infusion solution (57.2 [SD 8.7] versus 60.3 [SD 10.2] $\mathrm{mm} \mathrm{Hg}$; $p=0.024)$. Consequently, mean minimum systolic (77.7 [SD 17.1] versus 80.1 [SD 16.6] $\mathrm{mm} \mathrm{Hg;} p=$ 0.0398) and mean minimum diastolic blood pressure
(43.6 [SD 7.2] versus 45.7 [SD 8.6] $\mathrm{mm} \mathrm{Hg;} p=0.0485$ ) were significantly lower in patients randomized to $0.9 \%$ saline. Patients randomized to $0.9 \%$ saline over time had a mean arterial blood pressure, which was $4 \mathrm{~mm} \mathrm{Hg}$ lower than in patients receiving an acetatebuffered balanced solution during whole surgery $(95 \%$ CI: $1-7 \mathrm{~mm} \mathrm{Hg} ; p=0.009$ ). Fig. 3 gives mean and systolic blood pressure levels during surgery for patients receiving either $0.9 \%$ saline or an acetate-buffered balanced infusion solution. In the Cox regression analysis it could be shown that patients receiving catecholamines had significantly lower blood pressure levels before administration of catecholamines than patients without catecholamines (see Fig. 4). There was no difference in heart rate (normal 73 beats per minute \pm 12.6 versus acetate-buffered solution 74 beats per minute $\pm 12.2, p=0.66$ ) and central venous pressure (normal saline $9 \pm 10 \mathrm{mmH}_{2} \mathrm{O}$, acetatebuffered solution $8 \pm 5 \mathrm{mmH}_{2} \mathrm{O}, p=0.34$ ) between the groups.

Peak chloride levels were significantly higher in patients randomized to the normal saline group ( $109 \mathrm{mmol} / \mathrm{L}$ [107 to 111 ] versus $107 \mathrm{mmol} / \mathrm{L}$ [105 to 109]), $p=0.001$ as was fluctuation in serum chloride levels during surgery ( $4 \mathrm{mmol} / \mathrm{L}$ [3 to 6$]$ versus $3 \mathrm{mmol} / \mathrm{L}$ [2 to 5$]$ ]), $p=0.03$. Serum sodium levels were not significantly different between the groups ( $4 \mathrm{mmol} / \mathrm{L}$ [ 3 to 5 ] versus $3 \mathrm{mmol} / \mathrm{L}$ [2 to 5 ]), $p=0.92$. Acid base disturbances are described in more detail elsewhere [14].

\section{Discussion}

These are the first data from a prospective, randomized, controlled study comparing the effects of $0.9 \%$ saline and an acetate-buffered balanced crystalloid solution on hemodynamics in the perioperative period. We showed that perioperative use of a balanced crystalloid as a maintenance fluid is associated with better hemodynamic stability of patients with endstage renal disease receiving cadaveric renal transplantation. These findings are expressed by a significantly lower need for use of catecholamines for

Table 2 Catecholamines and vasopressors needed in the groups studied ( $n$, percentages, mean and standard deviations)

\begin{tabular}{|c|c|c|c|c|c|}
\hline \multicolumn{3}{|l|}{ Normal saline group } & \multicolumn{2}{|c|}{ Acetate-buffered balanced crystalloid group } & \multirow{2}{*}{$\begin{array}{l}P \text {-value } \\
0.15\end{array}$} \\
\hline Duration of anesthesia & 184 & \pm 73 & 166 & \pm 77 & \\
\hline Total intraoperative fluid (ml) & 1691 & \pm 664 & 1798 & \pm 679 & 0.34 \\
\hline Vasopressor & 56 & $73.7 \%$ & 50 & $67.6 \%$ & 0.47 \\
\hline $\begin{array}{l}\text { Cumulative vasopressor dose } \\
(\mu \mathrm{g} / \mathrm{kg} / \mathrm{min})\end{array}$ & 0.00011 & \pm 0.00017 & 0.000083 & \pm 0.000015 & 0.08 \\
\hline Catecholamines & 23 & $30 \%$ & 12 & $15 \%$ & 0.027 \\
\hline Fluid until vasopressor (ml) & 407 & \pm 287 & 735 & \pm 482 & 0.007 \\
\hline Time to catecholamines ( $\mathrm{min}$ ) & 68 & \pm 45 & 75 & \pm 60 & 0.0055 \\
\hline $\begin{array}{l}\text { Cumulative catecholamine } \\
\text { dose ( } \mu \mathrm{g} / \mathrm{kg} / \mathrm{min})\end{array}$ & 0.000492 & \pm 0.002311 & 0.000107 & \pm 0.00039 & 0.04 \\
\hline Time on catecholamines (min) & 141 & 74 & 175 & 75 & 0.6 \\
\hline
\end{tabular}




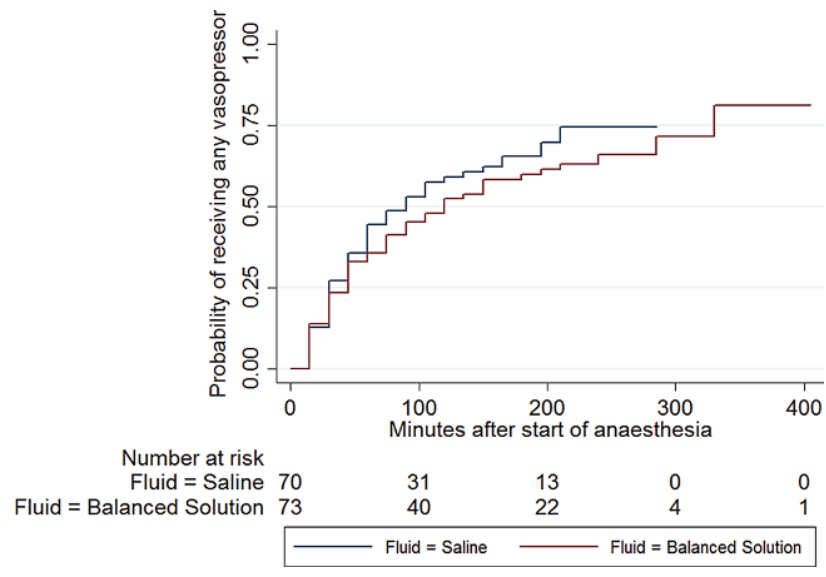

Fig. 2 Kaplan Meyer analysis: time to catecholamines
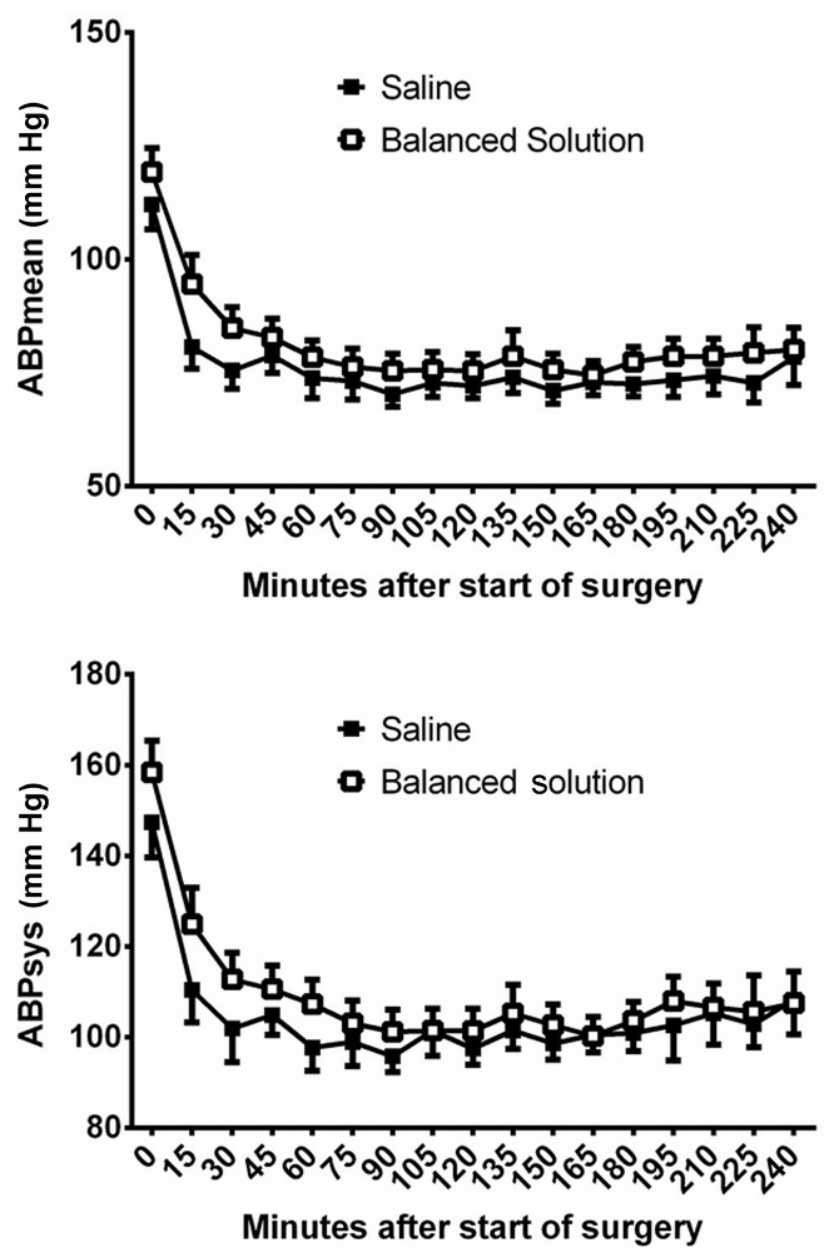

Fig. 3 Mean (upper panel) and systolic (lower panel) blood pressure levels in patients receiving either $0.9 \%$ saline or an acetate-buffered balanced infusion solution

hemodynamic support and higher systolic and mean arterial blood pressure levels.

The strength of the current study is explained by the study collective: all patients had end-stage renal disease and received cadaveric renal transplantation. This collective of patients is especially vulnerable to

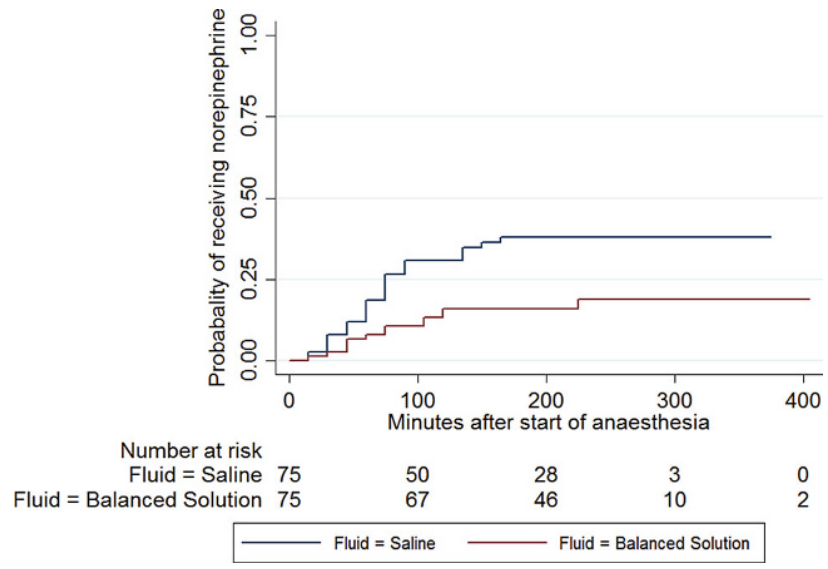

Fig. 4 Kaplan Meier analysis: probability to need norepinephrine

effects due to infusion solutions since they lack the capacity of the kidneys to rapidly compensate for electrolyte and acid-base derangements to a variable degree. Theoretically, this makes even slight effects due to the infusion solution obvious, which would not be seen in patients with normal kidney function or only after administration of far larger volumes of fluid.

We found a significantly lower need for catecholamines, a longer time to catecholamines and a lower cumulative catecholamine dose in the acetate-buffered group. The significantly better hemodynamic stability in patients receiving a balanced acetate-based infusate compared to normal saline might be related to A) acetate itself and B) hyperchloremia induced by normal saline.

So far no study has compared the hemodynamic effects of normal saline to an acetate-buffered balanced crystalloid; however, there is some older evidence that the use of sodium acetate may have an influence on the cardiovascular system. In 1978 Liang and Lowenstein infused acetate and pyruvate in to anesthetized dogs to measure their impact on circulation [15]. They found that increased acetate levels were associated with a significant increase in cardiac output [15]. Even though myocardial oxygen consumption increased during acetate infusion, the decrease in myocardial oxygen uptake and the increase in coronary sinus blood oxygen saturation suggest that an active coronary vasodilation which was not a result of the increased cardiac work takes place [15]. Acetate infusion also increased blood flow to the gastrointestinal tract, kidneys, intercostal muscles and diaphragm [15]. In another study by Conahan et al. on resuscitation fluid composition and myocardial performance during burn shock in guinea pigs, the authors were able to show that treatment with Ringer's acetate significantly improved cardiac output and contractility when compared to normal saline and Ringer's lactate [16]. In the same study Ringer's acetate was found to have better blood pressure stabilizing effects compared to Ringer's lactate and normal saline [16]. Concerning 
blood pressure stabilization three studies on sodium acetate found that such an infusion may have a positive effect on cardiac output but it lowers peripheral vascular resistance [17-19], a finding that we cannot confirm; however, it has to be born in mind that data on acetate and acetate-buffered crystalloid solutes and hemodynamics remain scarce and are mostly experimental. There is a lack of controlled randomized trials in humans that compare currently available crystalloid solutes with respect to hemodynamics and further research certainly should be encouraged.

In 2004 the study group around John Kellum showed in a model of experimental sepsis that infusion of chloride-rich crystalloids led to a decrease in arterial blood pressure in rodents compared to infusion of lactated Ringers [13]. In another crossover study on 12 healthy volunteers Chowdhury et al. found that a colloid, embedded in a balanced crystalloid solution, led to increased renal cortical tissue perfusion while the same concentration of colloid, embedded in $0.9 \%$ saline, did not result in improved renal perfusion [20]. A similar trial of this group in which 21 of $0.9 \%$ saline or a chloride-reduced, balanced crystalloid was administered to healthy volunteers showed that administration of $0.9 \%$ saline even resulted in a decline in renal blood flow velocity and renal cortical tissue perfusion [11]. Given this evidence, together with other recent studies on this subject [2, 21, 22], it is plausible that hyperchloremia induced by infusion of chloride-rich solutions, is the direct trigger for unfavorable hemodynamic effects, as seen in our current study. Only recently, large scale studies and meta-analysis showed that use of chloride-rich infusion solutions might be associated with adverse outcome [2, 23, 24]; however, a Cochrane review from 2012 still came to the conclusion that although balanced crystalloids are associated with less occurrence of hyperchloremia and concurrent metabolic acidosis, use of conventional solutions (i.e. $0.9 \%$ saline) can be considered safe in the perioperative period [25]. Additionally, a recently published randomized controlled trial comparing $0.9 \%$ saline to an acetatebuffered crystalloid solute found no differences in terms of acute kidney failure and renal replacement therapy [26]. Given the current data together with previously published studies in the field, the need for prospective randomized controlled trials is obvious. While studies comparing the currently available crystalloid solutes with mortality as the primary endpoint will be hard to perform due to the large patient numbers needed and probable issues with the financing of such a study, it seems applicable to perform studies focusing on patient hemodynamics or renal function.

\section{Limitations}

Our study has several limitations. The major drawback of this study is the lack of invasive hemodynamic monitoring such as esophagus Doppler, pul- monary artery catheter or thermodilution techniques. Additionally, blood pressure was monitored non-invasively, which was performed in order to preserve blood vessels in patients potentially in need of dialysis shunts in the future. Additionally, it has to be borne in mind that the original study was designed to investigate incidence rates of perioperative hyperkalemia, other electrolyte and acid-base disorders and not hemodynamics. Therefore, hemodynamic management followed hospital standard operating protocols (SOP but not a hemodynamic protocol specially designed for the present study. Additionally, the study was not blinded, so investigator bias is possible but not very likely as hemodynamics were not an outcome in the first study and hospital SOP's were followed. Nonetheless the results of the present study should be interpreted with some caution. We see our results as a first indiction that the choice of crystalloid may impact hemodynamic stability, but certainly further research needs to be done before an overall conclusion can be reached.

\section{Conclusion}

In conclusion, the results of the prospective, randomized, controlled trial suggest that use of an acetatebuffered, balanced infusion solution results in less occurrence of arterial hypotension and reduced need for use of catecholamines and cumulative catecholamine dose for hemodynamic support in the perioperative period. The more favorable hemodynamic outcome of patients receiving an acetate-buffered crystalloid solute may be attributed to increased cardiac output related to acetate as well as lower susceptibility for hyperchloremia and concurrent metabolic acidosis when compared to normal saline. Future randomized, controlled trials are certainly desirable to clarify the effects of current crystalloid infusates on hemodynamics in the perioperative field and the critically ill.

Author contributions C. A. Pfortmueller: assessment of data, evaluation of data, preparation of the manuscript, G.-C. Funk: evaluation of data, E. Potura: assessment of data, C. Reiterer: assessment of data, F. Luf: assessment of data, B. Kabon: planning of the study, preparation of the manuscript, W. Druml: preparation of the manuscript, E. Fleischmann: planning of the study, preparation of the manuscript, G. Lindner: planning of the study, assessment of data, evaluation of data, preparation of the manuscript.

\section{Funding Self-funding.}

Open access funding provided by Medical University of Vienna.

\section{Compliance with ethical guidelines}

Conflict of interest C. Pfortmueller, G.-C. Funk, E. Potura, C. Reiterer, F. Luf, B. Kabon, W. Druml, E. Fleischmann, and G. Lindner declare that they have no competing interests. 
Ethical standards The study was approved by the local institutional review board (EK 1048/2009 Oct 2009 and EK $1828 / 2014$ Oct 2014, Chairman Prof. E. Singer), of the Medical University of Vienna, Austria, and registered at a clinical trials registry (NCT01075750). Written informed consent was obtained from every patient included in the study.

Open Access This article is distributed under the terms of the Creative Commons Attribution 4.0 International License (http://creativecommons.org/licenses/by/4.0/), which permits unrestricted use, distribution, and reproduction in any medium, provided you give appropriate credit to the original author(s) and the source, provide a link to the Creative Commons license, and indicate if changes were made.

\section{References}

1. Lobo DN. Intravenous $0.9 \%$ saline and general surgical patients: a problem, not a solution. Ann Surg. 2012;255(5):830-2.

2. Shaw AD, Bagshaw SM, Goldstein SL, Scherer LA, Duan M, Schermer CR, Kellum JA. Major complications, mortality, and resource utilization after open abdominal surgery: $0.9 \%$ saline compared to Plasma-Lyte. Ann Surg. 2012;255(5):821-9.

3. Cecconi M, Corredor C, Arulkumaran N, Abuella G, Ball J, Grounds RM, Hamilton M, Rhodes A. Clinical review: Goaldirected therapy-what is the evidence in surgical patients? The effecton differentriskgroups. CritCare. 2013;17(2):209.

4. O'Malley CM, Frumento RJ, Bennett-Guerrero E. Intravenous fluid therapy in renal transplant recipients: results of a US survey. Transplant Proc. 2002;34(8):3142-5.

5. Noritomi DT, Pereira AJ, Bugano DD, Rehder PS, Silva E. Impact of Plasma-LytepH 7.4 on acid-base status and hemodynamics in a model of controlled hemorrhagic shock. Clinics (Sao Paulo). 2011;66(11):1969-74.

6. Hofmann-Kiefer KF, Chappell D, Kammerer T, Jacob M, Paptistella M, Conzen P, Rehm M. Influence of an acetateand a lactate-based balanced infusion solution on acid base physiology and hemodynamics: an observational pilot study. Eur J Med Res. 2012;17:21.

7. Zadak Z, Hyspler R, Hronek M, Ticha A. The energetic and metabolic effect of Ringerfundin (B. Braun) infusion and comparison with Plasma-Lyte (Baxter) in healthy volunteers. Acta Medica (Hradec Kralove). 2010;53(3):131-7.

8. Voigtsberger S, Urner M, Hasler M, Roth Z'Graggen B, Booy C, Spahn DR, Beck-Schimmer B. Modulation of early inflammatory response by different balanced and nonbalanced colloids and crystalloids in a rodent model of endotoxemia. PLoS ONE. 2014;9(4):e93863.

9. Story DA, Lees L, Weinberg L, Teoh SY, Lee KJ, Velissaris S, Bellomo R, Wilson SJ. Cognitive changes after saline or plasmalyte infusion in healthy volunteers: a multiple blinded, randomized, cross-over trial. Anesthesiology. 2013;119(3):569-75.

10. Keibl C, Sipos W, Ponschab M, Schlimp CJ. Blood biochemical changes in pigs after infusion with acetate-buffered or lactate-buffered crystalloid solutions. Lab Anim (NY). 2015;44(7):268-73.

11. ChowdhuryAH, CoxEF, Francis ST, Lobo DN.Arandomized, controlled, double-blind crossover study on the effects of 2 -Linfusions of $0.9 \%$ saline and plasma-lyte(R) 148 on renal blood flow velocity and renal cortical tissue perfusion in healthy volunteers. Ann Surg. 2012;256(1):18-24.

12. Wilkes NJ, WoolfR, MutchM, MallettSV,PeacheyT,Stephens $\mathrm{R}$, Mythen MG. The effects of balanced versus saline- based hetastarch and crystalloid solutions on acid-base and electrolyte status and gastric mucosal perfusion in elderly surgical patients. Anesth Analg. 2001;93(4):811-6.

13. Kellum JA, Song M, Venkataraman R. Effects of hyperchloremic acidosis on arterial pressure and circulating inflammatory molecules in experimental sepsis. Chest. 2004;125(1):243-8.

14. Potura E, Lindner G, Biesenbach P, Funk GC, Reiterer C, Kabon B, Schwarz C, Druml W, Fleischmann E. An acetatebuffered balanced crystalloid versus $0.9 \%$ saline in patients with end-stage renal disease undergoing cadaveric renal transplantation: a prospective randomized controlled trial. Anesth Analg. 2015;120(1):123-9.

15. Liang CS, Lowenstein JM. Metabolic control of the circulation. Effects of acetate and pyruvate. J Clin Invest. 1978;62:1029-38.

16. Conahan ST, Dupre A, Giaimo ME, Fowler CA, Torres CS, Miller HI. Resuscitation fluid composition and myocardial performance during burn shock. Circ Shock. 1987;23(1):37-49.

17. Ward RA, Wathen RL, Harding GB, Thompson LC. Comparative metabolic effects of acetate and dichloroacetate infusion in the anesthetized dog. Metab Clin Exp. 1985;34(7):680-7.

18. Burnier P, Tappy L, Jequier E, Schneeberger D, Chiolero R. Metabolic and respiratory effects of infused sodium acetate in healthy human subjects. Am J Physiol. 1992;263(6 Pt 2):R1271-1276.

19. Suokas A, Kupari M, Heikkila J, Lindros K, Ylikahri R. Acute cardiovascular and metabolic effects of acetate in men. AlcoholClin Exp Res. 1988;12(1):52-8.

20. ChowdhuryAH, CoxEF, Francis ST, Lobo DN.Arandomized, controlled, double-blind crossover study on the effects of 1 -Linfusions of $6 \%$ hydroxyethyl starch suspended in $0.9 \%$ saline (voluven) and a balanced solution (Plasma Volume Redibag) on blood volume, renal blood flow velocity, and renal cortical tissue perfusion in healthy volunteers. Ann Surg. 2014;259(5):881-7.

21. Yunos NM, Bellomo R, Hegarty C, Story D, Ho L, Bailey M. Association between a chloride-liberal vs chloride-restrictive intravenous fluid administration strategy and kidney injury in critically ill adults. JAMA. 2012;308(15):1566-72.

22. Nadeem A, Salahuddin N, El Hazmi A, Joseph M, Bohlega B, Sallam H, Sheikh Y, Broering D. Chloride-liberal fluids are associated with acute kidney injury after liver transplantation. Crit Care. 2014;18(6):625.

23. Krajewski ML, Raghunathan K, Paluszkiewicz SM, Schermer CR, Shaw AD. Meta-analysis of high- versus lowchloride content in perioperative and critical care fluid resuscitation. Br JSurg. 2015;102(1):24-36.

24. RaghunathanK, ShawA, Nathanson B, SturmerT, Brookhart A, Stefan MS, Setoguchi S, Beadles C, Lindenauer PK. Association between the choice of IV crystalloid and inhospital mortality among critically ill adults with sepsis. CritCare Med. 2014;42(7):1585-91.

25. Burdett E, Dushianthan A, Bennett-Guerrero E, Cro S, Gan TJ, Grocott MP, James MF, Mythen MG, O'Malley $\mathrm{CM}$, Roche AM, Rowan K. Perioperative buffered versus non-buffered fluid administration for surgery in adults. Cochrane Database Syst Rev. 2012;12:CD004089.

26. Young P, Bailey M, Beasley R, Henderson S, Mackle D, McArthur C, McGuinness S, Mehrtens J, Myburgh J, Psirides A, Reddy S, Bellomo R. Effect of a buffered crystalloid solution vs saline on acute kidney injury among patients in the intensive care unit: the SPLIT randomized clinical trial. JAMA. 2015;314(16):1701-10. 